Volume 15 - Número 1 - jan/jul de 2020

\title{
O ESTADO, AS DIFICULDADES E AS CONTRAMEDIDAS DO CURSO DE LÍNGUA PORTUGUESA NA CHINA CONTINENTAL SOB A ESTRATÉGIA "UM CINTURÃO E UMA ROTA" - TENDO A UNIVERSIDADE DE ESTUDOS INTERNACIONAIS DE SICHUAN COMO EXEMPLO
}

\section{THE STATE, DIFFICULTIES AND COUNTER-MEASURES OF THE PORTUGUESE LANGUAGE COURSE IN CONTINENTAL CHINA UNDER THE "ONE BELT AND ONE ROUTE" STRATEGY - HAVING THE UNIVERSITY OF INTERNATIONAL STUDIES OF SICHUAN AS AN EXAMPLE}

\begin{abstract}
RESUMO: Com o aquecimento global da estratégia "um Cinturão e uma Rota", desde 2016, os países de língua portuguesa têm expressado o seu desejo de se juntar aos países pertencidos a "Um Cinturão e Uma Rota", o que aumentou ainda mais a demanda por talentos em língua portuguesa, especialmente nas necessidades de formação dos "talentos compostos"2. O presente artigo aprensenta o exemplo da língua portuguesa da Universidade de Estudos Internacionais de Sichuan e combina o ensino de português para falantes de chineses. Com objetivo de analisar o estado da construção da língua portuguesa a partir dos aspectos de ensino e aprendizagem de língua portuguesa, plano letivo de curso, formação de talentos e consolidação de equipe de docentes. Esta pesquisa oferece ainda as propostas práticas para satisfazer a formação de "talentos compostos" , tais como construção da plataforma $\mathrm{MOOC}^{3}$ e o cultivo de talentos "multilínguas +" e etc. Espero fornecer alguma inspiração para a construção e o desenvolvimento do curso da língua portuguesa na China Continental sob o contexto de "Um Cinturão e Uma Rota".
\end{abstract}

PALAVRAS-CHAVE: Português. Ensino da língua portuguesa. China. Um cinturão e uma rota.

\begin{abstract}
With the global warming of the "The Belt and Road" strategy, since 2016, Portuguese-speaking countries have been expressing their desire to join the "The Belt and Road" countries, which has further increased the demand for talents in Portuguese language. Especially in the training needs of the composite talents, according to the national strategy, this article takes the example of Portuguese course from Sichuan International Studies University and combines the current situation of Chinese Portuguese course to analyze the state of Portuguese language construction. From the aspects of Portuguese language teaching, course plan, talent formation and teacher team consolidation with practical proposals, such as construction of the MOOC platform and the cultivation of "composite talents" and etc. I hope to provide some inspiration for the construction and development of the Portuguese language course of mailand China, under the context of "The Belt and Road".
\end{abstract}

KEY-WORDS: Portuguese. Portuguese language teaching. China. The Belt and Road.

\footnotetext{
1 Mestrado em Linguística Pela Universidade de São Paulo. Professora e coordenadora do Curso de Língua Portuguesa da Universidade de Estudos Internacionais de Sichuan(abreviada por SISU). Email: tangsijuan@gmail.com.

2 "talentos compostos", características profissionais necessárias para esta nova era .

3 A massive open online course (MOOC / mu:k/) is an online course aimed at unlimited participation and open access via the web.
} 
Volume 15 - Número 1 - jan/jul de 2020

\section{Introdução}

Em 17 de agosto de 2016, o Presidente Xi Jinping, da China, participou do Simpósio de Promoção da Construção de "Um Cinturão e Uma Rota" e proferiu um discurso importante, com ênfase especial no enfoque na comunicação de políticas, conectividade das instalações, livre comércio, circulação monetária e nas aspirações dos povos. O modelo e a plataforma de cooperação multidimensional permitirão, de acordo com essa estratégia, que a construção do "Um Cinturão e Uma Rota" beneficie as pessoas de todos os países ao longo do percurso. O povo é a pedra angular de outros aspectos da intercomunicação, e o assunto mais eminente na sociedade é a "linguagem de comunicação". A estratégia "Um Cinturão e Uma Rota" inclui condição de software e condição de hardware, sendo a linguagem um dos conteúdos importantes da construção de condição de software de "Um Cinturão e Uma Rota". Em outras palavras, a linguagem é também um ponto de entrada e ponto-chave da construção dessa condição de software. Afinal, mesmo para construir "estradas de pavimentação" e "pontes" a China não pode ignorar os problemas de linguagem e de integração em torno do objetivo estratégico (ZHANG, 2016, p. 3).

Para atender melhor a essa estratégia nacional chinesa e fortalecer os laços econômicos, comerciais, políticos e culturais com os países de língua portuguesa, a construção e o desenvolvimento científico dos cursos de língua portuguesa nas universidades e faculdades chinesas é particularmente importante. Atualmente, o português é idioma oficial das seguintes regiões geográficas: Portugal, Brasil, Angola, Moçambique, Guiné-Bissau, Cabo Verde, Timor-Leste, São Tomé e Príncipe e Macau. O seu uso abrange toda a Ásia, África, Europa e América do Sul e é uma das línguas mais faladas no mundo, com mais de 230 milhões de pessoas no mundo usando o português. Como a China está tornando-se gradualmente uma economia emergente no nundo, as relações comerciais e econômicas entre a China e os países de língua portuguesa ficam cada vez mais frequentes. De acordo com a Social Science Network (2014) da China , o Brasil foi o maior parceiro comercial da China na América Latina em 2013; a China é o maior parceiro comercial do Brasil, o maior importador e o maior destino de exportação, além da África. Angola atraiu várias empresas chinesas para lá se instalarem devido à enorme demanda pela construção de infraestrutura nos últimos anos. Em outubro de 2016, realizou-se em Macau, de 11 a 12 de dezembro, a $5^{\text {a }}$ Reunião Ministerial do Fórum de Cooperação Econômica e Comercial entre a China e os Países de Língua Portuguesa, que determinou a direção da cooperação econômica e comercial, as áreas e os métodos de cooperação entre a China e os países de língua portuguesa durante 2017-2019, em conformidade com o que foram assinados documentos relevantes e introduzindo a iniciativa e filosofia "The Belt and Road".

Em dezembro de 2018, a convite do presidente de Portugal, Marcelo Rebelo de Sousa, o presidente chinês Xi Jinping fez uma visita oficial a Portugal de 4 a 5 de dezembro. No último dia desse encontro, após reunião com o primeiro-ministro português, António Costa, os líderes dos dois países testemunharam a assinatura de vários documentos de cooperação bilateral, como o Memorando de Entendimento entre o Governo da República Popular da China e o Governo da República de Portugal sobre a promoção conjunta da construção de "Um Cinturão e Uma Rota" (2018) . Além disso, líderes de alto nível dos países de língua portuguesa, como Brasil e Angola, também expressaram seu desejo de aderir à referida 
Volume 15 - Número 1 - jan/jul de 2020

iniciativa estratégica.

\section{$2 \mathrm{O}$ desenvolvimento do curso de língua portuguesa na China Continental}

Desde a abertura do curso de língua portuguesa no Instituto de Radiodifusão de Pequim (hoje renomeado como a Universidade de Comunicação da China) na década de 1960, o curso de língua portuguesa da China continental já tem uma história de mais de 50 anos (LI, 2012, p. 35). Ao longo do caminho, encontramos muitas dificuldades na construção profissional, especialmente em relação às necessidades de desenvolvimento internacional da China.

Desde 2006, a escala profissional em língua portuguesa das universidades chinesas entrou num período de rápido crescimento. O número de universidades que abrem os cursos de língua portuguesa já chegou a 43 (HAN, 2019, p. 208). Existem, principalmente três modos de universidades que têm cursos de língua portuguesa. O primeiro são as Universidades que se dedicam específicamente ao ensino de línguas estrangeiras: Universidade de Estudos Internacionais de Xangai (SHISU), Universidade de Estudos Estrangeiros de Guangdong (GDUFS), Universidade de Línguas e Cultura de Pequim (BLCU), Universidade de Línguas Estrangeiras de Pequim (BFSU), Universidade de Estudos Internacionais de Pequim (BISU), Universidade de Estudos Internacionais de Xi'an (XISU) e Universidade de Estudos Internacionais de Sichuan (SISU). O sengundo é as universidades abrangentes multidisciplinares: Universidade de Pequim (PKU), Universidade de Nankai (NKU), Universidade Sun Yat-Sen (SYSU), Universidade de Comunicação da China (UCC), e outras mais. Por fim, o terceiro modo refere-se às faculdades privadas e empresariais: Faculdade de Nanguang da Universidade de Comunicação da China, Faculdade de Chengdu da Universidade de Estudos Internacionais de Sichuan (SISU), Faculdade de Negócios Nanguo da Universidade de Estudos Estrangeiros de Guangdong, e outras mais.

Do ponto de vista da escala de matrículas, a cada ano verifica-se um número específico de vagas oferecidas em português. Algumas faculdades e universidades adotam o método de matricular alunos a cada dois anos. O tamanho da turma geralmente é inferior a 30, que é uma forma de ensinar em turmas pequenas com objetivo de garantir o efeito de ensino. Em termos dos planos letivos, a maioria dos cursos de língua portuguesa concentra-se na língua e na literatura. $\mathrm{O}$ curso é direcionado para o desenvolvimento das quatro habilidadeds: compreensão oral, oralidade, leitura e escrita em português.

2.1 Estabelecimento do Curso de Língua Portuguesa na Universidade de Estudos Internacionais de Sichuan (SISU)

Aprovada pelo Ministério da Educação e pela Comissão Municipal de Educação de Chongqing em 2011, a Universidade de Estudos Internacionais de Sichuan (doravante SISU) foi oficialmente aprovada para o programa de graduação em português. Devido à extrema falta de docentes de português em 2011, a universidade abriu somente um curso de segunda língua estrangeira de português e, após mais de um ano de preparação, o curso de graduação em português na SISU começou oficialmente a matricular alunos em 2012.

O curso de português da SISU também é o único de português de licenciatura no 
Volume 15 - Número 1 - jan/jul de 2020

sudoeste da China. As disciplinas principais são as seguintes: Português de Nível Básico, Português de Nível Intermediário, Português de Nível Avançado, incluindo também cursos de Vocabulário Técnico em Português, Redação, Compreensão Oral, etc.

O objetivo do curso é desenvolver habilidades básicas de linguagem nas quatro habilidades de compreensão oral, oralidade, leitura e escrita. Além disso, os alunos precisam de receber formação profissional de tradução. No entanto, os alunos têm que ter o conhecimento da literatura, da história, da economia, da cultura, da religião e da sociedade dos países de língua portuguesa. Com base nas vantagens da plataforma da SISU, o programa realiza ativamente intercâmbios e cooperação internacionais, justamente por isso assinando convênios com as Universidades portuguesas de Aveiro e do Minho, além duma brasileira que é Universidade de São Paulo. Normalmente os alunos da SISU fazem intercâmbios no terceiro ano letivo de licencitura. Atualmente, a equipe de docentes de língua portuguesa possui 8 professores, incluindo 6 chineses, 2 estrangeiros (1 português, 1 brasileiro) e a idade média da equipe é 31 anos. Todos os professores têm experiências ou habilitações de estudar português nos países de língua portuguesa. Não há funcionários com títulos profissionais sêniores ou doutorado no corpo docente. A taxa de emprego dos graduados de português destaca-se na SISU. Desde os primeiros graduados em 2016, a taxa de emprego tem se mantido acima de $95 \%$. A maioria dos estudantes vai para os ministérios nacionais, grandes empresas estatais, empresas emergentes de internet ou fazer mestrado nas universidades estrangeiras.

\section{Os problemas na construção de cursos de língua da China Continental sob contexto de "Um Cinturão, Um Caminho"}

\subsection{Desafios relacionados ao plano científico do curso com vistas ao mercado de trabalho}

Nas faculdades e universidades tradicionais que abrem os cursos de língua portuguesa, o currículo concentra-se basicamente em "ouvir, falar, ler, escrever e traduzir". O curso planeja-se principalmente para treinar e consolidar a base linguística dos alunos. Essas "habilidades básicas" são, de facto, a pedra angular para quem aprende a língua, mas, à medida que o número de formandos aumenta, o feedback dos alunos concentra-se na ansiedade de desenvolvimento sustentável da carreira.

Como a universidade ensina apenas as técnicas linguísticas e tradução de português, é fácil que se limitem as possibilidades de carreira. Por outro lado, as empresas também tendem a colocar graduados nos cursos de língua portuguesa apenas em "Postos de tradução" , ou cargos de outro nome como "Representantes acreditados no exterior", mas, na verdade, eles ainda desenpenham o papel de tradutores.

A confusão comum entre estudantes e empresas reflete um problema embaraçoso: atualmente, a maioria dos programas de treino de talentos baseados em "habilidades linguísticas dos alunos" orientados por universidades não pode mais atender às necessidades das empresas de hoje. Em outras palavras, o programa de curso já não se revela propício ao desenvolvimento a longo prazo para os estudantes de língua portuguesa em relação ao desenvolvimento sustentável da carreira. Em 2015, A Comissão Nacional de Desenvolvimento e Reforma, o Ministério das Relações Exteriores e o Ministério do Comércio promulgaram em conjunto o documento intitulado "Visão e Ação para Promover a 
Volume 15 - Número 1 - jan/jul de 2020

Construção do Cinturão Econômico da Rota da Seda e da Rota Marítima da Seda do Século XXI" em que se consta uma cooperação variada e extensiva entre a China e os países ao longo da rota.

O documento "Visão e Ação" abrange a área de construção de infraestruturas de transporte e energia à construção da rede de ramificações de comunicação, do desenvolvimento de carvão, petróleo e gás, minerais metálicos à cooperação técnica no desenvolvimento de energia limpa, como água, energia nuclear, energia eólica e energia solar, da conectividade da moeda, comércio e investimento à cooperação regulatória financeira. Também abre cooperação nos campos da arte, da cultura, do turismo e da tecnologia, o que envolve muitas indústrias.

Essas proveitosas formas de cooperação propõem a demanda pela qualidade de talentos linguísticos, refletidos principalmente em dois aspectos:

1) É necessário cultivar um grupo de habilidades profissionais linguísticas, além de estar familiarizados com as condições e a cultura nacionais do país de destino para poder participar de traduções e trocas culturais;

2) É preciso cultivar um grande número de talentos linguísticos compostos com visão e experiência internacionais numa determinada disciplina, capaz de se envolver na construção de uma indústria especializada e participar de assuntos internacionais (SUN; LIU, 2018, p. 42). Em resposta às necessidades da construção nacional da estratégia "Um Cinturão e Uma Rota”, o curso de língua portuguesa da SISU ajustou o programa de treino de talentos e experimentou o modo de treino de talentos compostos. Em particular, o currículo aumentou e fortaleceu alguns outros conhecimentos por meio de algumas disciplinas, tais como Vocabulário Técnico em Português (português+ vocabulário de engenharia), Econômico e Comercial (português+economia+comércio). No entanto, devido às limitações de professores e mesmo aos créditos escolares, esses cursos compostos contam com dificuldades de aplicação, tais como o efeito nos professores que se tornam mais tensos na preparação árdua das aulas, pois as horas de aprendizagem não são suficientes por causa de espaço e tempo, resultando num efeito de aprendizado distante do ideal.

\subsection{Desafios relacionados à Qualificação dos Docentes}

A partir de 2011, o número das universidades que abrem o curso de português começou a mostrar "crescimento explosivo" no país, tanto em termos de número de universidades que abrem o curso como na escala de matrículas dos alunos. O período de rápido desenvolvimento é sempre acompanhado pela escassez de docentes.

YE (2014, p. 42) apontou no "Algumas reflexões sobre o rápido desenvolvimento do português" que a rápida expansão da profissão de idioma português nas universidades chinesas é principalmente acompanhada pelos dois principais problemas a seguir. A primeira é a escassez de professores ou, mais precisamente, a falta de recursos para professores qualificados. Ele explicou que muitos professores de língua portuguesa em faculdades e universidades são recém-formados. Ele também expressou a sua preocupação com a falta de material didático de língua portuguesa: várias disciplinas de língua portuguesa não contam com materiais correspondentes ao seu programa de ensino. Esse constitui-se um grande 
Volume 15 - Número 1 - jan/jul de 2020

desafio para novos professores com experiência e qualificações académicas insuficientes.

A partir da situação dos professores da SISU, também podemos perceber a situação geral dos professores de língua portuguesa no país. O perfil dos professores é jovem que carecem de líderes com vasta experiência em ensino e pesquisa. Os professores de língua portuguesa têm tarefas árduas de ensino e baixos títulos acadêmicos.

\subsection{Desafios relativos ao material didático}

Muitos professores de língua portuguesa frequentemente enfrentam a situação de carência de material no processo de ensino. A situação para os anos letivos mais avançados é particularmente evidente.

Para os docentes bem jovens, isso dificulta a tarefa de preparar as aulas. É necessário obterem os materiais didáticos pela Internet ou por outros meios. Por um lado, isso provoca aos docentes grande preocupação na preparação de uma aula. Por outro lado, os materiais dispersos tornam a aprendizagem dos alunos não sistemática e o efeito do ensino é bastante reduzido.

Devido à falta de material didático, os professores ainda usam livros didáticos publicados há mais de 10 anos (TANG, 2015), o que desfavorece que os estudantes tenham contato com a realidade contemporânea. A língua é dinâmica, com constante variação e mudança, assim como as discussões temáticas na economia e na cultura nacionais dos países-alvo. Os livros didáticos não atualizados são propícios a uma formação mais geral, pois saem da graduação com defasagem de conhecimentos relativoa à sociedade e à língua que estudaram.

\section{As propostas práticas, a construção de cursos de língua portuguesa}

Em resposta à questão de como cultivar um talento multidisciplinar com uma visão internacional, o curso de português pode aprender com as experiências avançadas que outras instituições já realizaram. Nesta seção, exporemos algumas ferramentas que podem ser auxiliares nas práticas docentes chinesas.

\subsection{A plataforma MOOC e o cultivo de talentos "multilínguas +"}

Considerando o modelo "lingua não comun $^{4}+$ profissional" desenvolvido pelas universidades americanas (WEN, 2016, p. 31) e "lingua não comun + cursos em artes e ciências humanas", podemos refletir sobre seus benefícios, tais como os vistos no exemplo do Curso de Administração de Turismo, Economia e Comércio Internacional, e outros mais (ZHANG, 2009, p. 66). Nessa lógica, promove-se o aprofundamento do fluxo internacional de estudantes, pois nesse modelo de formação para estudantes prevê-se o esquema " $3+1$ ", quer dizer, 3 anos de estudo no doméstico +1 no exterior.

\footnotetext{
${ }^{4} \mathrm{Na}$ china, refere-se a uma língua de minoria, que exclui inglês, chinês, francês, russo, espanhol, árabe.
} 
Volume 15 - Número 1 - jan/jul de 2020

O Departamento de Português da SISU fez tentativas correspondentes. Junto às disciplinas obrigatórias do curso de graduação em língua portuguesa, foram adicionados o "Perfil do País de Língua Portuguesa", "Português Comercial", "Vocabulário Técnico" e outros "cursos compostos". Espera-se que os alunos vivenciem outras valências profissionais além das linguísticas por meio desses cursos, tais como: compreensão da história local, costumes, economia e políticas dos países de língua portuguesa, para que os alunos tenham uma visão internacional e tornem-se "talentos compostos", o que é mais necessário na nova era.

Obviamente, isso não é suficiente para cultivar um "talento composto" genuíno e qualificado e pode não satisfazer às necessidades da estratégia "Um Cinturão e Uma Rota" para talentos "portugueses+", tais como especializados em Economia, Comércio, Finanças, Engenharia, Assistência Médica e Direito. Devido às limitações das horas de crédito dos alunos e à dificuldade de ensino pelos docentes entre os diferentes departamentos da universidade, esse modo de formação de talentos compostos confronta muitas dificuldades na sua implementação.

Com o surgimento da plataforma MOOC, mais faculdades de línguas estrangeiras juntaram-se à equipe que produz o conteúdo do curso on-line, aproveitando as vantagens desses espaços virtuais e das plataformas MOOC em combinação com o modo "Aula Invertida ${ }^{5}$, em que os vídeos de aulas concisos e animados incentivam os alunos a conduzirem uma aprendizagem mais independente (FU, 2016, p. 196). Notou-se que, por meio de cursos on-line, não apenas reduziu-se o tempo de "aprendizagem passiva" dos alunos, mas também tornaram a aprendizagem dos alunos mais personalizada, rompendo as limitações de tempo e espaço e aumentando o interesse dos alunos em "aprendizado ativo". O processo de aprendizado tornou-se mais individualizado e produtivo.

Ao mesmo tempo, no curso de talentos compostos, é possível convidar o professor de língua portuguesa e outros professores de outros cursos a produzirem aulas on-line em conjunto. Um exemplo seria juntar "Curso de Português+Curso de Relações Internacionais", e permitir ao professor de língua portuguesa que efetue o trabalho concentrando-se nas técnicas de linguagem, enquanto o outro professor se aprofunda em temas das relações internacionais, tais como as teorias e as práticas específicas. Essa cooperação, além de romper as barreiras do tempo e do espaço gerando um novo modo integrado de cursos compostos. Ademais, esse modo poderia ser utilizado repetidamente e nunca haveria limite quanto ao número de alunos, e também pode ser implementado em vários cursos on-line, como "Português+ Finanças" e "Português + Direito".

\subsection{Investimento em professores por projetos nacionais}

As primeiras universidades que oferecem o curso da língua portuguesa devem assumir a liderança, formar ativamente estudantes de pós-graduação e recrutar estudantes de doutorado. Em particular, criam-se mais programas de mestrado e/ou doutorado de língua portuguesa para formar mais talentos de ensino na língua.

\footnotetext{
${ }^{5}$ A Aula Invertida is defined by Schoolology.com as a blended learning model where traditional ideas about homework and classroom activities are reversed or "flipped."
} 
Volume 15 - Número 1 - jan/jul de 2020

Atualmente, a Universidade de Estudos Estrangeiros de Guangdong lançou conjuntamente um curso de mestrado de português com a Universidade de Coimbra (Portugal) e já começou as primeiras matrículas. Com essa parceria estratégica, haverá uma melhora nas qualificações dos professores, daí ser uma ação muito gratificante. Por outro lado, o Estado e as universidades podem apoiar os professores portugueses com recursos e projetos para melhorar continuamente o seu nível de pesquisa quer acadêmica quer científica.

Os Estados Unidos lançaram uma importante estratégia de linguagem em 2006 que é chamado o National Security Language Initiative (NSLI). O programa NSLI dedica-se a aumentar o número de pessoas que aprendem línguas estrangeiras importantes nos Estados Unidos a partir da escola primária e a aumentar o número de professores que ensinam os idiomas mais significativos. Existem vários pontos dignos de referência para o programa NSLI: um é fornecer aos professores de línguas programas de formação de curto prazo no exterior para melhorar rapidamente o nível de ensino; o segundo é oferecer aos professores excelentes oportunidades de graduação no exterior para melhorar a estrutura de habilitações de professores de português; o terceiro, é para fortalecer o treino de talentos linguísticos não comuns na fase de pós-graduação para fazer uma boa reserva de talentos de professores do futuro (SUN; LIU, 2018). Essas ações não apenas ajudarão os professores a melhorar as suas qualificações acadêmicas, mas também garantirão que os professores façam progressos nas visitas aos países-alvo a curto prazo. Esse contato é fundamental para que se entendam a cultura dos países-alvo e seja possível ensinar os alunos com conhecimentos mais avançados e atualizados.

4.3 Incentivo à elaboração de materiais didáticos, livros didáticos ambos em chinês e português

Tendo em vista a escassez de recursos didáticos e a obsolescência dos livros didáticos de português, além da experiência fraca de ensino de jovens professores. É uma lacuna ainda por preencher a constituição de equipes com professores experientes no ensino de língua portuguesa para a elaboração de livros didáticos, pois somente em equipe que reune forças várias é possível que se organizem a pesquisa e a elaboração de materiais didáticos .

Se, por um lado, a Universidade de Estudos Estrangeiros de Pequim, a Universidade de Macau, o Instituto Politécnico de Macau e outras instituições tradicionais que contam com mais experiências devem trabalhar em conjunto para promover a cooperação entre as universidades para realizar fórums ou seminários académicos em português, por outro lado, a falta de livros didáticos de língua portuguesa não é apenas para quem estuda portuguê, mas também para os estrangeiros que têm interesse em aprender chinês.

Com a promoção e implementação da estratégia "Um Cinturão e Uma Rota", a China precisa fazer com que os países de língua portuguesa compreendam amplamente a língua e a cultura chinesas. Professores e outros especialistas em cultura e línguas precisam trabalhar em conjunto com os livros didáticos relacionados à cultura chinesa para que as pessoas dos países de língua portuguesa e da China se entendam melhor mutuamente. 
Volume 15 - Número 1 - jan/jul de 2020

\section{Conclusão}

Garantir o fornecimento de talentos de qualidade em língua portuguesa é uma condição importante para favorecer a implementação da estratégia nacional "Um cinturão e uma rota" nos países de língua portuguesa de modo que a intercompreensão seja de grande importância.

Embora existam atualmente mais de 40 universidades chinesas que abrem o curso de língua portuguesa, em termos de quantidade parece ser algo muito expressivo e de grande demanda, no entanto precisamos enfrentar o desafio da qualidade, de modo a atender às necessidades da estratégia "Um Cinturão e Uma Rota". Ao longo de nossa exposição, elencamos alguns desafios que podem ser superados se considerarmos o potencial resultado positivo. Tais desafios revelam-se no campo do planejamento do currículo, da formação dos professores, e do material didático.

\section{Referências}

FU, H. Y. Aproveitando os cursos on-line para cultivar talentos internacionais "multilíngues +" de língua portuguesa. Shangai: Pesquisa de práticas de ensino, 2016. p. 196.

HAN, T. G. O relatório sobre o desenvolvimento da cooperação entre a China e os países de língua portuguesa de 2019: Análise da Qualidade e Percurso da Formação de Talentos Portugueses na China. Pequim: Editora de Literatura de Ciências Sociais, 2019. p. 208.

LI, C. S. Ensino de português na década de 1960s da República Popular da China . Macau: O Primeiro Fórum Internacional do Ensino de Português, 2012. p. 35-42.

SUN,Q.; LIU, B. Q. Sob a iniciativa "One Belt One Road" Pesquisa sobre o estado e o caminho de desenvolvimento do treinamento de talentos em uma linguagem de minoridade. Pequim: China Higher Education Research, 2018. p. 41-46.

TANG, S. J. Necessidades e dificuldades: uma breve análise sobre livros didáticos de português como ferramenta interativa para professores e alunos. São Paulo: Biblioteca Eletrónica, Universidade de São Paulo, Brasil, 2015. p. 3-5.

WEN, Q. F. Formação de talentos linguísticos sob contexto de "Belt and Road". Pequim: Languing Strategies Research, 2016. p. 31.

YE, Z. L. Reflexões sobre o rápido desenvolvimento do ensino da língua portuguesa em chinês. Macau: Editor do Instituto de Politécnico de Macau, 2014. p. 42-54.

ZHANG Z. G. Problemas de linguagem na construção de "Um Cinturão e Uma Rota". Aplicação de linguagem, 2016 . p. 3.

ZHANG, X. Q. Exploração e Prática de "Linguagem Profissional + Não Universal" para o Cultivo de Talentos Compostos da ASEAN, tendo como exemplo a Universidade Guangxi de Nacionalidades. Teaching Management Research, 2009. p. 66.

Submetido em 30/04/20

Aceito em 13/08/20 